\title{
Chemotherapeutic agents used in the treatment of childhood malignancies have direct effects on growth plate chondrocyte proliferation
}

\author{
H Robson, E Anderson, O B Eden, O Isaksson ${ }^{1}$ and S Shalet \\ Christie Hospital NHS Trust, Manchester M20 4BX, UK and ${ }^{1}$ RCEM, University of Goteberg, Goteberg, Sweden \\ (Requests for offprints should be addressed to H Robson, Department of Tumour Biochemistry, Christie Hospital NHS Trust, Wilmslow Road, Manchester \\ M20 4BX, UK)
}

\begin{abstract}
Short stature is one of the most well recorded long term sequelae for adult survivors of childhood malignancies. It has become increasingly apparent that cytotoxic chemotherapy, as well as craniospinal irradiation, has a major impact on growth, but there are virtually no studies which explore the mechanisms by which these cytotoxic drugs affect growth. We have used an in vitro system to investigate the direct effects of a range of chemotherapeutic agents on the proliferative responses of rat tibial growth plate chondrocytes, both in suspension and monolayer culture.

The glucocorticoids and purine anti-metabolites reduced chondrocyte proliferation both in monolayer and suspension cultures and this resulted from an increase in cell doubling times with a concomittant reduction in the numbers of S phase cells. DNA damaging agents (e.g.
\end{abstract}

actinomycin-D) were also able to reduce chondrocyte proliferation, both in monolayer and suspension culture. This, however, was the result of a cell cycle arrest and subsequent cell death. In our studies, methotrexate had no significant effect on the proliferative responses of the chondrocytes either in monolayer or suspension culture.

These results indicate direct effects of a range of chemotherapeutic agents on the proliferative responses of growth plate chondrocytes. Both cytostatic and cytotoxic effects were observed although the impact of either the potential loss of cells from the proliferative pool during chondrocyte differentiation, or the reduction in the rate of chondrocyte turnover on long bone growth remains to be elucidated.

Journal of Endocrinology (1998) 157, 225-235

\section{Introduction}

Recent reports suggest that the chemotherapy used in the treatment of childhood malignancies has an effect on growth that is independent of the hypothalamic-pituitary axis, and may reduce the final height of surviving children. Growth retardation following treatment has been demonstrated in several studies (Olshan et al. 1992, Ogilvy-Stuart \& Shalet 1995) and there is radiological evidence that the epiphyseal growth plate is damaged in children with acute lymphoblastic leukaemia (ALL) who have received sustained and intensive chemotherapy (Wollner et al. 1980). This is further supported by a large collaborative study between the Manchester, Nottingham and Sheffield paediatric oncology centres (Davies et al. 1994) in which the effects of combination chemotherapy and cranial irradiation on final height and body proportions were examined in a cohort of 142 children treated for ALL. Of the children in the study for whom sitting height measurements were available, $81 \%$ had relatively shorter backs than legs and it was suggested that this disproportion might be due to effects of the chemotherapy on the large numbers of epiphyses that are found in the spine. Despite the prevailing clinical evidence it is surprising that there have been few investigations examining local effects of cytotoxic chemotherapy on growth, particularly in terms of long bone growth. The most detailed in vitro experimental studies were performed by Morris (1981), who examined the effects of seven different cytotoxic drugs on insulin-like growth factor-I (IGF-I)-stimulated $\left[{ }^{35} \mathrm{~S}\right]$ sulphate and $\left[{ }^{3} \mathrm{H}\right]$ thymidine uptake in a porcine costal cartilage bioassay. These studies indicated that cytotoxic chemotherapy may have a direct effect on the response of chondrocytes to changes in the growth hormone $(\mathrm{GH})$ / IGF-I axis. More recently, the glucocorticoid, dexamethasone, was shown to slow proximal tibial growth rate when infused for 4 weeks in 6-week-old rabbits compared with the contralateral vehicle-treated limb (Baron et al. 1994). Following cessation of the dexamethasone treatment, local catch-up growth was observed in the affected growth plate only, suggesting a mechanism intrinsic to the growth plate. In order to address the issue 
of the effects of chemotherapy on long bone growth, an in vitro system of rat tibial chondrocytes in monolayer and suspension culture was used. Rat tibial growth plates provide a readily available and well characterised source of chondrocytes which, when grown in suspension culture in vitro, parallel the differentiation events observed in vivo and are thus an excellent model of chondrogenesis. We have found that a range of chemotherapeutic agents commonly used in the treatment of ALL have direct effects on chondrocyte proliferation in vitro.

\section{Materials and Methods}

\section{Isolation and culture of chondrocytes}

Chondrocytes were isolated from the tibial epiphyseal growth plates of 21-day-old male Sprague-Dawley rats as described by Lindahl et al. (1987). In brief, epiphyseal growth plates were dissected from the rat proximal tibiae with the aid of a binocular microscope. Pooled growth plates from $4-5$ animals were digested in a $25-\mathrm{cm}^{2}$ tissue culture flask (Falcon, Oxford, Oxon, UK) for 6-7 h at $37^{\circ} \mathrm{C}$ with $0.05 \%$ clostridium collagenase $/ 0.02 \%$ DNAse I (w/v; Sigma, Poole, Dorset, UK) in Ham's F12 medium (GIBCO Life Technology, Paisley, Strathclyde, UK). After isolation, the cells were washed three times in serum-free medium (SFM) and counted using a haemocytometer. Cell viability at the end of the incubation was generally $>95 \%$ as determined by the trypan blue dye exclusion technique. Subsequently, cells were diluted to a concentration of $5 \times 10^{4}$ cells $/ \mathrm{ml}$ in F12 medium supplemented with $10 \%$ newborn calf serum (NCS; GIBCO Life Technology) and $50 \mu \mathrm{g} / \mathrm{ml}$ ascorbic acid (AA) (Sigma; F12/NCS/AA), before seeding at $5 \times 10^{5}$ cells to each $75-\mathrm{cm}^{2}$ tissue culture flask (Falcon). Cells were incubated at $37^{\circ} \mathrm{C}$ in air containing $5 \% \mathrm{CO}_{2}$ and the culture medium changed after 4 days. Cells were cultured for at least 3 days post confluence, after which they were trypsinised, washed in culture medium and counted. The second culture period was performed either in suspension culture stabilised with agarose or in monolayer culture in 8-well chamber slides, and 12- or 96-well tissue culture plates.

\section{Chemotherapeutic agents}

The chemotherapeutic agents employed in all experiments were prednisolone, dexamethasone, cisplatin, carboplatin, etoposide, actinomycin-D, 6-mercaptopurine, 6thioguanine and methotrexate which were all obtained from the Christie Hospital Pharmacy. The doses of each chemotherapeutic agent used ranged around the peak plasma levels achieved with these agents in vivo.

\section{Sulphorhodamine B (SRB) proliferation assay}

Proliferation was measured in monolayer culture using the SRB assay (Skehan et al. 1990). By means of a direct assessment of protein content, this agent provides a colorimetric endpoint as a highly sensitive measure of drug-induced cytotoxicity.

Chondrocytes were seeded in 96-well tissue culture plates (Falcon) at a density of 5000 cells/well in F12/ NCS/AA. Cells were incubated for $24 \mathrm{~h}$ at $37^{\circ} \mathrm{C}$ in air containing $5 \% \mathrm{CO}_{2}$ before the addition of fresh medium (F12/NCS) with or without the chemotherapeutic agents over the range $0 \cdot 01-10 \mu \mathrm{g} / \mathrm{ml}$. Cultures were terminated after $0,1,3$ and 6 days by fixation in 10\% trichloroacetic acid (Sigma) for $1 \mathrm{~h}$ at $4{ }^{\circ} \mathrm{C}$. Plates were then washed five times in tap water and air dried before the addition of $0.4 \%$ SRB (Sigma) in $0.1 \%$ acetic acid (BDH, Poole, Dorset, $\mathrm{UK})$ for $1 \mathrm{~h}$ at room temperature (RT). Following subsequent washing of the wells with $0 \cdot 1 \%$ acetic acid to remove unbound dye, $100 \mu 110 \mathrm{mM}$ Tris-base (Sigma) was added to each well. Absorption was measured on a microplate reader (Molecular Devices) at $540 \mathrm{~nm}$ within 30 min of adding the Tris-base $(10 \mathrm{mM})$.

\section{Culture of chondrocytes in suspension stabilised with agarose}

Cells were cultured in agarose according to Benya \& Shaffer (1982). In brief, $60 \mathrm{~mm}$ non-tissue culture-treated Petri dishes (Falcon) were pre-coated with $1 \%$ standard low melting point agarose (autoclaved at $112{ }^{\circ} \mathrm{C}$ for 45 min.; Bio-Rad, Richmond, CA, USA). Low melting point agarose was autoclaved as above and mixed with an equal volume of F12 to give an agarose concentration of 1\%. Cells and F12 were then mixed to give a final agarose concentration of $0 \cdot 5 \%$ containing 10000 cells $/ \mathrm{ml}$. Three millilitres of this gel solution were added to each petri dish (30 000 cells/dish) and the gel was allowed to solidify at $4{ }^{\circ} \mathrm{C}$ for $15 \mathrm{~min}$ before the addition, on top of the gel, of Dulbecco's modified Eagle's medium (DMEM; GIBCO Life Technology) mixed with an equal volume of $\mathrm{F} 12+20 \%$ foetal bovine serum (FBS; Biowhittaker, Wokingham, Berks, UK) with or without addition of the chemotherapeutic agents over the range $0 \cdot 01-10 \mu \mathrm{g} / \mathrm{ml}$. Thereafter, the cultures were screened for adherent cell clusters of more than three cells. No such clusters were seen at the start of culture in any experiments presented in this study. The suspension cultures were maintained for 14 days at $37^{\circ} \mathrm{C}$ in air containing $5 \% \mathrm{CO}_{2}$ with a medium change after 7 days to DMEM/F12 mix $+10 \%$ FBS alone.

\section{Clonal assay}

Suspension cultures were terminated by fixation in $4 \%$ paraformaldehyde (Sigma) in phosphate-buffered saline (PBS) and stained with alcian blue $(0.5 \%$ in $0.04 \mathrm{M}$ hydrochloric acid; Sigma) to identify colonies producing glycosaminoglycans. Colonies from triplicate dishes were optically counted and a colony was defined as a cluster of 
cells with matrix stained by alcian blue and a diameter $>50 \mu \mathrm{m}$. Colony numbers and any marked variations in colony size were recorded.

\section{Cell counts and flow cytometry}

Chondrocytes were seeded in 12-well plates (Falcon) at a density of 50000 cells/well in F12/NCS/AA and incubated for $24 \mathrm{~h}$ before the addition of fresh medium (F12/NCS) with or without chemotherapeutic agents at single submaximally effective doses, as indicated in the figures. Cells were then cultured for up to 7 days at $37^{\circ} \mathrm{C}$ in air containing $5 \% \mathrm{CO}_{2}$. At varying time points during this incubation, cells from duplicate wells were trypsinised and counted using a haemocytometer. The remaining cells were then washed and resuspended in a small volume of PBS containing $0 \cdot 1 \%$ BSA (Sigma), $0 \cdot 1 \%$ Triton X-100 $(\mathrm{BDH})$ and $50 \mu \mathrm{g} / \mathrm{ml}$ propidium iodide (PI; Sigma). Cell cycle analysis was performed within $1 \mathrm{~h}$ of PI addition using a minimum of $1 \times 10^{4}$ cells and a Becton Dickinson Facscan.

\section{Bromodeoxyuridine (BrdU) immunohistochemistry}

Chondrocytes were seeded to 8-well Lab Tek tissue culture chamber slides (Nalge Nunc International, Naperville, IL, USA) at 10000 cells/well in F12/ NCS/AA and incubated for $24 \mathrm{~h}$ before the addition of fresh medium (F12/NCS) with or without chemotherapeutic agents at single submaximally effective doses as indicated in Table 1. Cells were cultured for 4 days at $37^{\circ} \mathrm{C}$ in air containing $5 \% \mathrm{CO}_{2}$, after which time the medium was removed and the cells washed. Fresh medium with $100 \mu \mathrm{mol} \mathrm{BrdU}$ (Sigma) was then added to each well and the cells continuously labelled during an overnight incubation. Wells without BrdU acted as controls. Cultures were subsequently terminated by fixation in 4\% paraformaldehyde in PBS for 10 min at RT.

Following a PBS wash, nuclei were exposed by a 30-min incubation at RT with $1 \mathrm{M} \mathrm{HCl}(\mathrm{BDH})$ followed by a further 30-min incubation at RT with $0 \cdot 1 \mathrm{M}$ $\mathrm{Na}_{2} \mathrm{~B}_{4} \mathrm{O}_{7}$ (Sigma). Incubation with a mouse anti-BrdU antibody (Beckton Dickinson, Bedford, MA, USA), 1:100 in PBS, was performed at RT for $1 \mathrm{~h}$ followed by three washes in PBS. Bound antibody was detected by the addition of a biotinylated rat anti-mouse antibody (Vector, Peterborough, UK) diluted 1:100 in PBS for $1 \mathrm{~h}$ at RT, followed by exposure to the preformed avidin-biotin complex (Vector) for $30 \mathrm{~min}$ at RT. Sites of peroxidase activity were visualised with diaminobenzidine tetrahydrochloride plus $0 \cdot 2 \%(\mathrm{v} / \mathrm{v})$ hydrogen peroxide (Sigma). Finally, the cells were counterstained with 5\% haematoxylin, dehydrated, cleared in histoclear and mounted in DPX mountant. Labelled cells from five separate random fields were counted under the light microscope.

\section{Statistical analysis}

Mean values were compared by analysis of variance. Comparisons between two means were made using the unpaired Student's $t$-test. Differences were considered to be significant when $P \leq 0 \cdot 05$.

\section{Results}

\section{Morphology of monolayer cultured chondrocytes}

Following plating of $5 \times 10^{5}$ cells to $75 \mathrm{~cm}^{2}$ flasks, a change in cell morphology was observed with time. Cells changed from being initially flattened and mesenchymallike to appearing characteristically polygonal or round. The plating of rat growth plate chrondrocytes at a low density allowed us to select for a population of cells with a high proliferative capacity, thus optimising the measurements made in our subsequent studies. Certainly, an inverse relationship has been shown between cell proliferation and the expression of differentiation markers, such that when the cells are directly plated at confluence (a condition where cell multiplication is impaired) differentiation of chrondrocytes and hence maturation readily occurs (Cancedda et al. 1992). Post-confluent chondrocytes tended to be located in dense clusters and extracellular matrix (EM) production was apparent, as visualised by alcian blue staining. Matrix proteoglycan synthesis is also indicative of type II collagen production in these cells, a further characteristic of the chondrogenic phenotype. Dedifferentiated cells started to detach from the culture dish a few days after becoming confluent.

\section{Proliferation in monolayer culture}

Proliferation was measured at 0, 1, 3 and 6 days following the treatment of rat tibial chondrocytes with the chemotherapeutic agents in monolayer culture. In all treatment arms, cell numbers $24 \mathrm{~h}$ after the addition of the drugs were not significantly different from day 0 values. Whilst significant effects on the numbers of cells $(P<0 \cdot 05)$ were observed in the presence of these agents after both 3 and 6 days of culture, in general these effects were greater at day 3 when compared with the untreated control. The effects of these agents on cell numbers at day 3 are shown in Fig. 1a,b,c. 6-Mercaptopurine and 6-thioguanine significantly $(P<0 \cdot 05 ; n=5)$ reduced cell numbers above a threshold concentration of $0 \cdot 1 \mu \mathrm{g} / \mathrm{ml}$ for both agents although little dose-dependency was observed with either agent between $0 \cdot 1$ and $10 \mu \mathrm{g} / \mathrm{ml}$ (the maximum dose used in these studies). At $10 \mu \mathrm{g} / \mathrm{ml}, 6$-mercaptopurine and 6-thioguanine significantly reduced cell numbers by $18 \cdot 31 \pm 2 \cdot 01 \%$ and $13 \cdot 68 \pm 4 \cdot 33 \%$ respectively $(P<0 \cdot 05$; $n=5$ : Fig. $1 a)$. In contrast, methotrexate had no significant effect on cell number, compared with the control, between $0 \cdot 01$ and $50 \mu \mathrm{g} / \mathrm{ml}(n=5)$. 

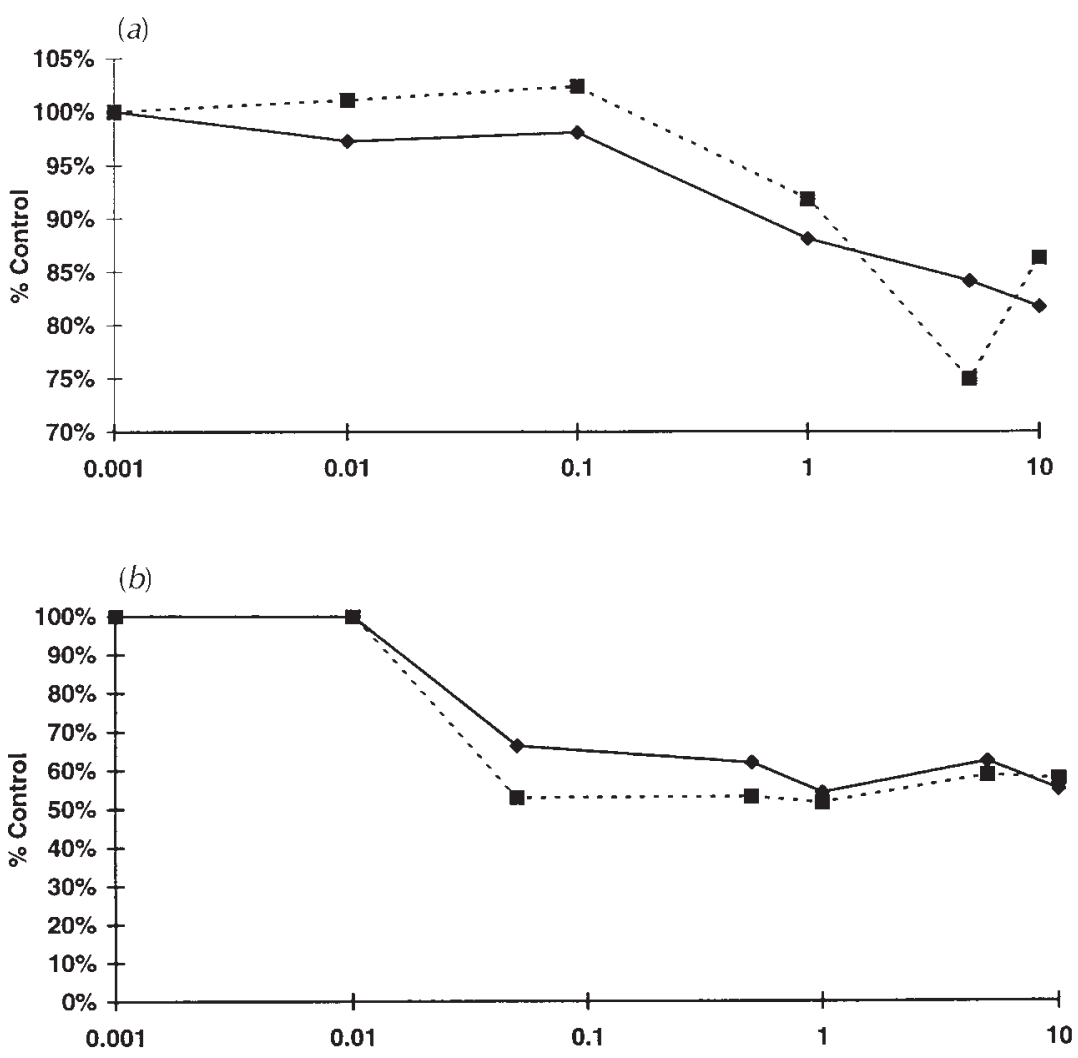

(c)

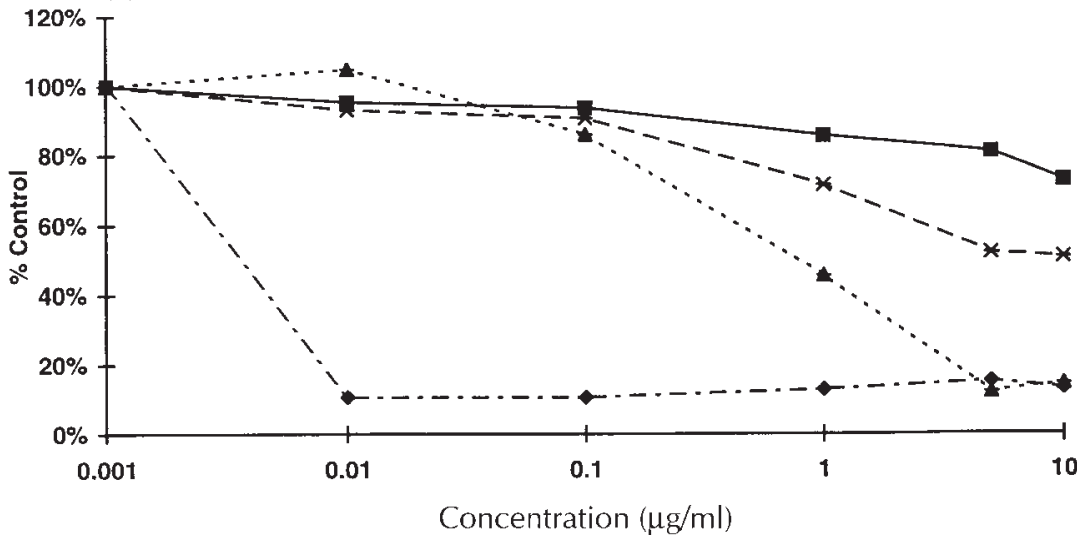

Figure 1 Dose-response curves of rat proximal tibia growth plate chondrocytes treated with (a) 6-mercaptopurine $(\bullet)$ and 6-thioguanine $(\mathbf{\square})$, (b) prednisolone $(\bullet)$ or dexamethasone $(\boldsymbol{\square})$ and $(c)$ carboplatin $(\boldsymbol{\square})$, cisplatin $(\boldsymbol{\Delta})$, etoposide $(\times)$ or actinomycin-D ( ), $24 \mathrm{~h}$ after plating 5000 cells/well in a 96-well plate. Chemotherapeutic agents were present continuously during the 3-day incubation. Cells were fixed and stained as described in Materials and Methods. Values are expressed as a percentage of medium alone-treated controls and are the means \pm S.D. from five determinations in a single representative experiment.

Both prednisolone and dexamethasone significantly $(P<0 \cdot 005 ; n=5)$ reduced cell numbers only above a threshold dose of $0 \cdot 01 \mu \mathrm{g} / \mathrm{ml}$ after which there was no further dose-dependency (Fig. 1b). The reduction in cell numbers observed at $0.01 \mu \mathrm{g} / \mathrm{ml}$ was 1.5 times greater for dexamethasone than for prednisolone. 


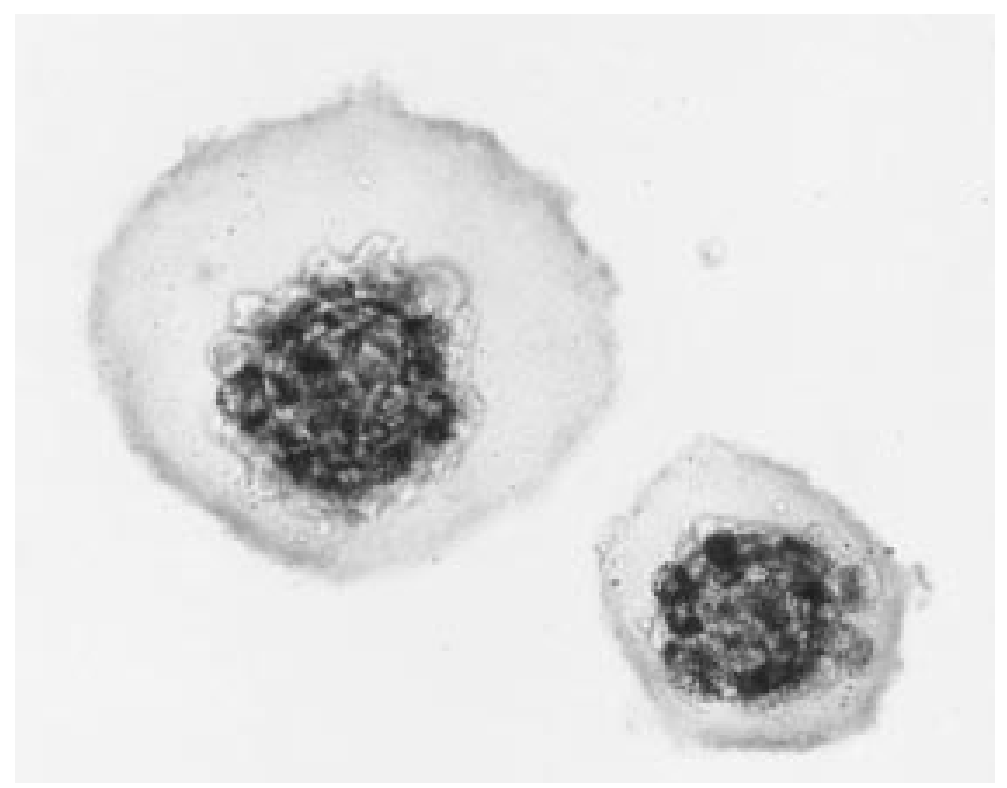

Figure 2 Chondrocyte colonies from epiphyseal cartilage in suspension culture. Chondrocytes were isolated from growth plates of the proximal tibia of 21-day-old male rats and cultured for 14 days in suspension culture stabilised with agarose. Cultures were terminated by fixation in buffered $4 \%$ paraformaldehyde and colonies were observed after staining with alcian blue $(0.5 \%$ in $0.04 \mathrm{M}$ hydrochloric acid) (magnification $\times 100$ ).

At the maximum dose employed $(10 \mu \mathrm{g} / \mathrm{ml})$, the DNA damaging agents significantly reduced chondrocyte cell numbers $(P<0 \cdot 05 ; n=5)$ with an order of potency: actinomycin-D $>$ cisplatin $>$ etoposide $>$ carboplatin (Fig. 1c). For both carboplatin and etoposide the reduction in cell numbers was dose-dependent above a threshold concentration of $0 \cdot 1 \mu \mathrm{g} / \mathrm{ml}$, whilst cisplatin dose-dependency occurred above $0 \cdot 01 \mu \mathrm{g} / \mathrm{ml}$. In the presence of actinomycin$\mathrm{D}$, however, cell numbers were significantly reduced at a concentration of $0.01 \mu \mathrm{g} / \mathrm{ml}(P<0 \cdot 001 ; n=5)$ but remained unchanged at higher concentrations of this drug. At this concentration cell numbers were below that of the day 0 values, indicative of cell death.

The reduction in cell numbers caused by these agents were not significantly different whether they were present in the culture medium for $1 \mathrm{~h}$ or continuously throughout the experiment (results not shown).

\section{Colony formation in suspension culture}

Rat tibial epiphyseal chondrocytes from 21-day-old rats formed small colonies after a culture period of 7 days. After 14 days of culture, the colonies were easily detected under the light microscope. Colonies consisted of varying numbers of cells embedded in a matrix containing proteoglycans, as identified by alcian blue staining (Fig. 2). The cloning efficiency (CE) described by the formula

$$
\mathrm{CE}=\frac{\text { No. of colonies counted }}{\text { Total no. of cells plated }} \times 100
$$

was $3 \cdot 86 \pm 0 \cdot 003 \%$ in control cultures $(n=9)$.

Prednisolone and dexamethasone significantly inhibited colony formation $(P<0 \cdot 005 ; n=9)$ once a threshold dose was reached (Fig. 3b). Consistent with our observations in monolayer culture, a difference in potency between these two agents was noted, such that the threshold dose for dexamethasone was 10 times lower than for prednisolone $(0 \cdot 1 \mu \mathrm{g} / \mathrm{ml}$ and $1 \mu \mathrm{g} / \mathrm{ml}$ respectively). At inhibitory concentrations of these glucocorticoids, although no colony formation was observed, single cells remained in suspension culture that appeared characteristic of a 'resting' or 'stem cell' population. The cells, often found in pairs, were small in size and showed no EM production.

6-Mercaptopurine and 6-thioguanine significantly $(P<0 \cdot 005 ; n=6)$ reduced colony formation in suspension culture (Fig. 3a). For example, cloning efficiency was reduced in the presence of $10 \mu \mathrm{g} / \mathrm{ml} \mathrm{6-mercaptopurine}$ and $10 \mu \mathrm{g} / \mathrm{ml}$ 6-thioguanine by $59 \cdot 5 \pm 4 \cdot 1 \%$ and $34.9 \pm 9 \cdot 63 \%$ of the controls respectively.

Etoposide, cisplatin, carboplatin and actinomycin-D were all extremely cytotoxic resulting in a total absence of colony formation and the loss of single cells from agarose cultures at concentrations $\geq 1 \mu \mathrm{g} / \mathrm{ml}$ in each instance. 
(a)

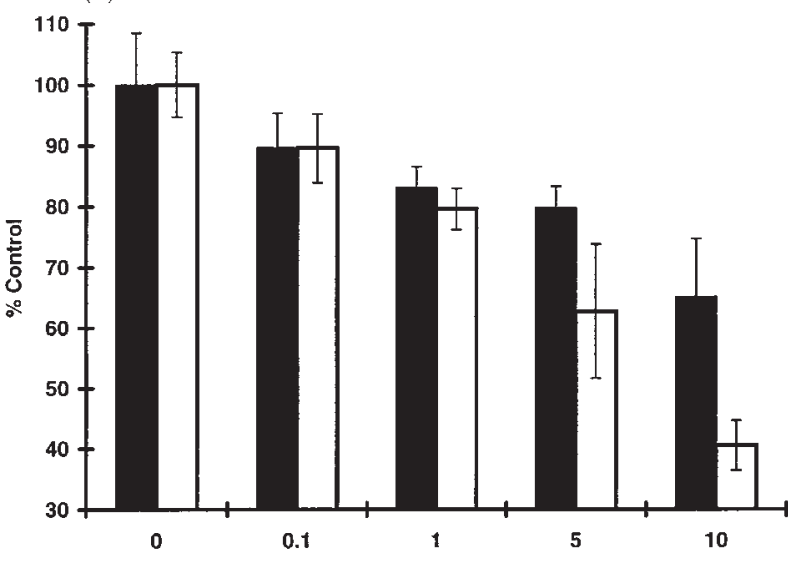

(b)

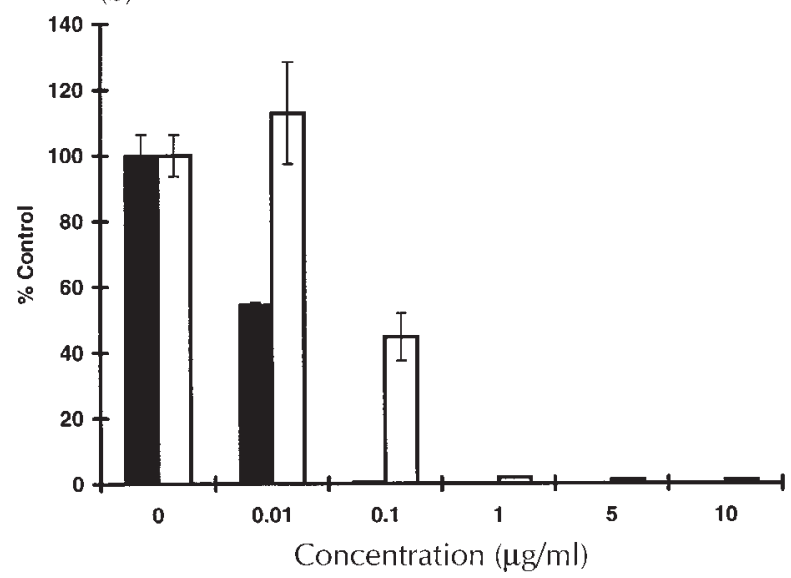

Figure 3 Effects of (a) 6-thioguanine (solid bars) or 6-mercaptopurine (open bars) and (b) dexamethasone (solid bars) or prednisolone (open bars) on the cloning efficiency of rat proximal tibial growth plate chondrocytes. Chondrocytes, 30000 per dish, were grown in suspension culture stabilised with agarose. Drugs in DMEM/F12+20\% FBS were added to the cultures. After 7 days the medium was changed to DMEM/F12+10\% FBS alone and the cultures incubated for a further 7 days. Following fixation in buffered $4 \%$ paraformaldehyde, colonies $>50 \mu \mathrm{m}$ were counted using a light microscope. Values are expressed as a percentage of medium alone-treated controls and are the means \pm S.D. from (a)

2 separate experiments $(n=6)$ (b) 3 separate experiments $(n=9)$.

However, methotrexate had no significant effect on the cloning efficiency compared with controls.

The size distribution of colonies was not significantly affected by the addition of any of the drugs over the range of concentrations used.

\section{Cell cycle kinetics}

For analysis of the immediate cytokinetic effects of the chemotherapeutic agents, chondrocyte doubling times, DNA content and BrdU incorporation were determined. The doubling time of exponentially growing untreated chondrocytes in monolayer culture was $39 \cdot 8 \pm 4 \cdot 3 \mathrm{~h}$ (Table 1) and a typical DNA histogram is shown in Fig. $4 a$.

The glucocorticoids, prednisolone $(5 \mu \mathrm{g} / \mathrm{ml})$ and dexamethasone $(5 \mu \mathrm{g} / \mathrm{ml})$ produced a significant $(P<0 \cdot 005$; $n=5)$ prolongation of chondrocyte doubling times in monolayer culture to $>4$ days (Table 1 ). This result was paralleled by a significant $(P<0 \cdot 005 ; n=5)$ reduction in the numbers of BrdU-labelled cells (Table 1).

The DNA damaging agents cisplatin $(1 \mu \mathrm{g} / \mathrm{ml})$, carboplatin $(10 \mu \mathrm{g} / \mathrm{ml})$ and etoposide $(1 \mu \mathrm{g} / \mathrm{ml})$ all inhibited cell cycle progression. In the presence of carboplatin and etoposide this was characterised by an early G2/M arrest at $24 \mathrm{~h}$, with an associated decrease in the numbers of G1 cells (Fig. 4b,d; Table 2). This effect was maintained, and accompanied at 7 days, by the loss of cells as indicated by the sub-G1 peak. Cisplatin, meanwhile, produced an accumulation of cells in S phase at $24 \mathrm{~h}$, followed by a G2/M arrest at $48 \mathrm{~h}$ (Fig. $4 c$; Table 2). Again, at 7 days cell loss was apparent. Actinomycin-D $(0 \cdot 1 \mu \mathrm{g} / \mathrm{ml})$ was highly cytotoxic when present in the chondrocyte cultures such that a $>95 \%$ cell loss occurred. In keeping with its lack of effect on proliferation, methotrexate $(5 \mu \mathrm{g} / \mathrm{ml})$ had no significant effect on cell doubling times (Table 1), numbers of BrdU-labelled cells ( $n=5$; Table 1 ) or cell cycle kinetics (Table 2).

Both 6-mercaptopurine $(10 \mu \mathrm{g} / \mathrm{ml})$ and 6-thioguanine $(10 \mu \mathrm{g} / \mathrm{ml})$ caused a small but significant $(P<0 \cdot 05 ; n=5)$ increase in the mean cell doubling times in monolayer culture from $39 \cdot 8 \pm 4 \cdot 3$ to $46 \cdot 2 \pm 3 \cdot 2$ and $41.9 \pm 2 \cdot 6 \mathrm{~h}$ respectively (Table 1 ), although no changes in cell cycle distribution were observed (Table 2). A significant reduction $(P<0 \cdot 05 ; n=5)$ in the numbers of BrdU-labelled cells was observed in the presence of both agents (Table 1).

\section{Discussion}

Growth plate activity determines the length of the vertebral column and the length of the long bones. During the process of longitudinal bone growth, cells from the germinal zone bordering the bony epiphysis differentiate and start clonal expansion within the proliferative zone. Subsequently, these cells stop dividing, mature and become a part of the hypertrophic zone. Finally, in the zone of calcification the cells degenerate and are incorporated into the metaphyseal bone (Hunziker 1994, Price et al. 1994). This phenotypic flexibility of the chondrocytes in vivo can be mimicked in vitro by cells growing in a suspension culture stabilised with agarose. In the present study chondrocytes were grown in both monolayer and suspension culture. Whilst results from the studies in monolayer cultures provide important information concerning the proliferative capacity of the chondrocyte population as a whole, this is only one aspect of the regulation of long bone growth. For this reason we also studied these cells in a suspension culture assay. This not 
Table 1 Cell doubling time and $\mathrm{S}$ phase fraction in rat proximal tibial growth plate chondrocytes following incubation for three days with or without chemotherapeutic agents. Doubling times were determined in a single experiment and are the mean \pm S.E.M. $(n=5)$. $S$ phase fractions were measured using BrdU immunohistochemistry. Values are the mean \pm S.D. from a single representative experiment $(n=5)$

\section{Doubling times}

(h)

Agent
Control
Prednisolone $(5 \mu \mathrm{g} / \mathrm{ml})$
Dexamethasone $(5 \mu \mathrm{g} / \mathrm{ml})$
6-Mercaptopurine $(10 \mu \mathrm{g} / \mathrm{ml})$
6-Thioguanine $(10 \mu \mathrm{g} / \mathrm{ml})$
Methotrexate $(5 \mu \mathrm{g} / \mathrm{ml})$

$39 \cdot 8 \pm 4 \cdot 3$

$96 \cdot 2 \pm 5 \cdot 2^{* *}$

$98 \cdot 7 \pm 4 \cdot 1^{* *}$

$46 \cdot 2 \pm 3 \cdot 2^{*}$

$41 \cdot 9 \pm 2 \cdot 6^{*}$

$43 \cdot 7 \pm 5 \cdot 2 \mathrm{~ns}$
BrdU-labelled

cells $(\%$ control)

${ }^{*} P<0 \cdot 05,{ }^{*} P<0 \cdot 005$, ns not significant, compared with control (Students $t$-test).

only allows the cells to be studied in isolation by measuring their ability to form colonies but it also provides an established in vitro model of chondrogenesis (Lindahl et al. 1987) such that morphological differences as the cells progress towards hypertrophy can be analysed with time. As a result of the chondrocytic isolation from whole growth plates of the proximal tibiae of normal rats, cells grown in suspension culture were heterogeneous in terms of their differentiation and maturation. This results in the formation of either small or large size colonies depending on whether the cells are derived from the proliferative or stem progenitor cells, respectively, within the growth plate (Lindahl et al. 1987). We found that the distribution of small and large size colonies was unaffected by any of the agents used and thus it is possible that they affected chondrocytes at all stages of maturation.

Both dexamethasone and prednisolone, although effective drugs in the treatment of ALL, significantly suppress growth in children (Van Metre \& Pinkerton 1959, Falliers et al. 1963). Indeed, in our study dexamethasone and prednisolone, above a threshold concentration, significantly reduced the proliferation and cloning efficiency of chondrocyte cells. BrdU incorporation into these cells suggested that either an interruption or slowing of DNA replication had occurred with these agents or, alternatively, that a significant proportion of the cells were no longer cycling. It is unlikely that the latter is the case, however, since analysis of the DNA histograms following a 48-h incubation of cells with either prednisolone or dexamethasone indicated that the majority of the cells were cycling and undergoing DNA synthesis, albeit rather slowly (Table 2). There is some evidence to suggest that dexamethasone may be more effective than prednisolone in the treatment of ALL (Kaspers et al. 1996) and whilst this is important for the treatment of childhood malignancies we should be aware that this increased potency may also impact upon growth plate chondrocytes. Certainly, in suspension culture dexamethasone was ten times more potent than prednisolone in terms of reducing chondrocyte cloning efficiency, which is consistent with a 7 -fold increase in potency observed with this agent in vivo (Kaspers et al. 1996). However, despite the inability of dexamethasone- or prednisolone-treated cells to form colonies in suspension culture, single cells, having characteristics of those cells found in the stem or reserve cell layer of the growth plate, clearly remained in culture. During chondrocyte differentiation the resting or stem cells have an extremely long generation time and act merely as a pool from which daughter cells are fed into the adjacent proliferating cell layer for subsequent clonal expansion. As we have already mentioned, however, our chondrocyte population was heterogeneous in terms of its origin from within the growth plate, and thus a proportion of the cells must be derived from the proliferative layer. Nevertheless, it is possible that these agents do act by suppressing stem cell proliferation, preventing their differentiation to IGF-I-responsive cells and thereby delaying senescence. In a study examining the differentiation of 3T3-F442A fibroblasts, it was reported that continued treatment with dexamethasone inhibits their terminal differentiation to the adipocyte-like phenotype (Pairault \& Lasnier 1987). Certainly, in the rabbit proximal tibial growth plate in vivo, dexamethasone was shown to slow the growth rate compared with a contralateral vehicletreated control. This was followed by local catch-up growth that was restricted to the affected growth plate (Baron et al. 1994). Under physiological conditions in the rat, each stem cell undergoes $\approx 40-50$ cell divisions. Each cell division gives rise to approximately 30 hypertrophic chondrocytes and each hypertrophic chondrocyte per column contributes approximately $30 \mu \mathrm{m}$ linear growth (Kember 1971). The slower division of stem cells would, therefore, delay growth. However, if the subsequent proliferation of non-stem daughter cells was also suppressed, then the glucocorticoids may also reduce the numbers of hypertrophic chondrocytes arising from each stem cell division. A decrease in clone size per stem cell division may lead to irreversible loss of linear growth. 
Oh $\quad 24 h \quad 48 h$

$168 \mathrm{~h}$

(a)
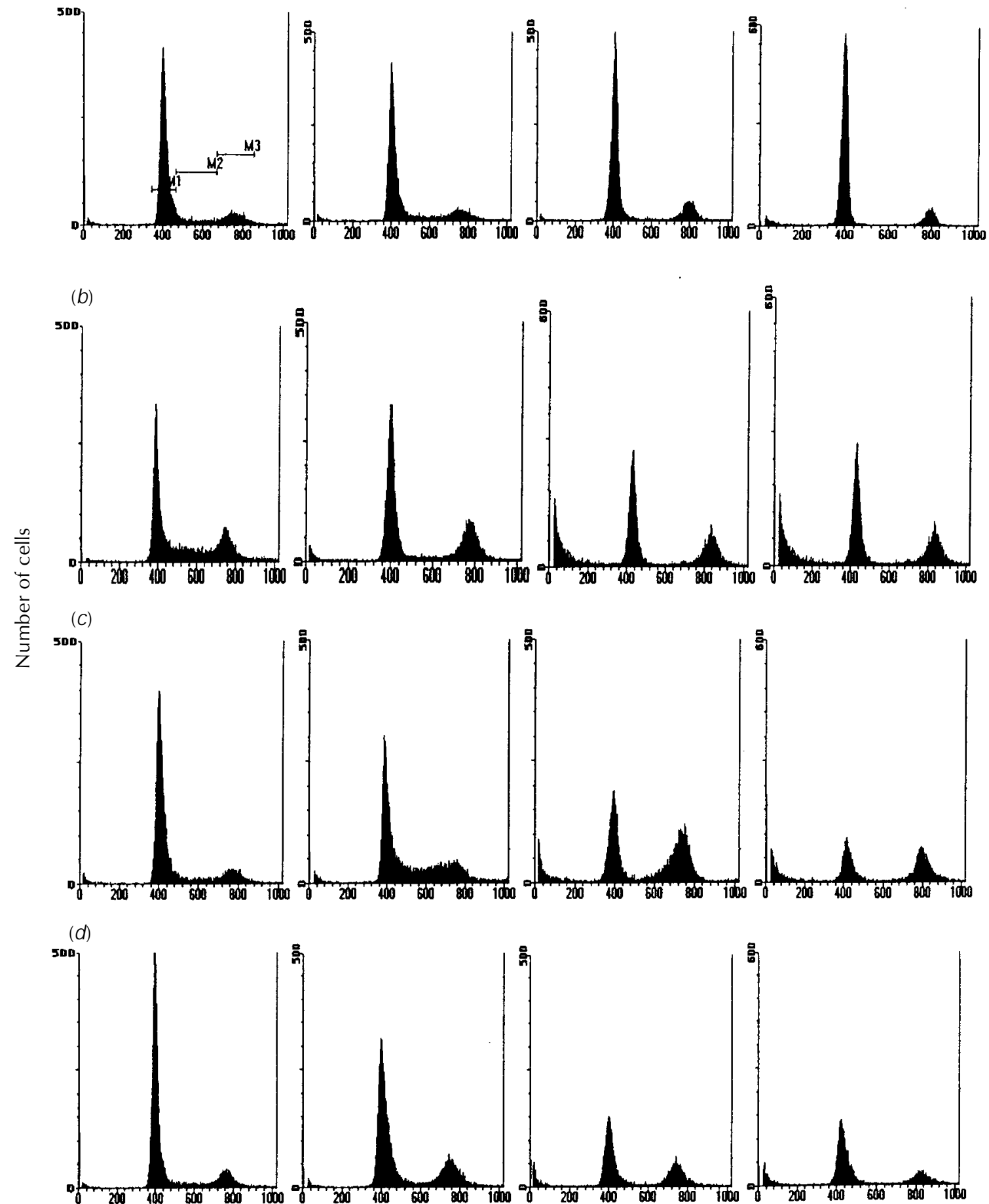

Figure 4 Changes in the cell cycle kinetics of exponentially growing chondrocyte cells at 0, 24, 48 and $168 \mathrm{~h}$ following treatment with (a) medium alone, (b) carboplatin $(10 \mu \mathrm{g} / \mathrm{ml})$, (c) cisplatin $(1 \mu \mathrm{g} / \mathrm{ml})$ and $(d)$ etoposide $(1 \mu \mathrm{g} / \mathrm{ml})$. Cells for flow cytometry were prepared as described in Materials and Methods. DNA histograms are ungated and show G1 (M1), S (M2) and G2/M (M3) peaks. Sub-G1 peaks are indicative of cellular apoptosis. 
Table 2 Cell cycle phase distribution of exponentially growing chondrocyte cells following incubation for $48 \mathrm{~h}$ with or without chemotherapeutic agents. Cells in each phase of the cell cycle were analysed in a single representative experiment and expressed as a percentage of the total cells counted in an ungated histogram

Cell cycle phase (\% total cells)

Agent
Control
Prednisolone $(5 \mu \mathrm{g} / \mathrm{ml})$
Dexamethasone $(5 \mu \mathrm{g} / \mathrm{ml})$
6-Mercaptopurine $(10 \mu \mathrm{g} / \mathrm{ml})$
6-Thioguanine $(10 \mu \mathrm{g} / \mathrm{ml})$
Cisplatin $(1 \mu \mathrm{g} / \mathrm{ml})$
Carboplatin $(10 \mu \mathrm{g} / \mathrm{ml})$
Etoposide $(1 \mu \mathrm{g} / \mathrm{ml})$
Methotrexate $(5 \mu \mathrm{g} / \mathrm{ml})$

Control

Prednisolone $(5 \mu \mathrm{g} / \mathrm{ml})$

Dexamethasone $(5 \mu \mathrm{g} / \mathrm{ml})$

6-Thioguanine $(10 \mu \mathrm{g} / \mathrm{ml})$

Cisplatin $(1 \mu \mathrm{g} / \mathrm{ml})$

Etoposide $(1 \mu \mathrm{g} / \mathrm{ml})$

Methotrexate $(5 \mu \mathrm{g} / \mathrm{ml})$

\begin{tabular}{|c|c|c|}
\hline G1 & $S$ & $\mathrm{G} 2 / \mathrm{M}$ \\
\hline $67 \cdot 79$ & $4 \cdot 60$ & $13 \cdot 61$ \\
\hline $77 \cdot 48$ & $2 \cdot 20$ & $11 \cdot 62$ \\
\hline $77 \cdot 02$ & $2 \cdot 08$ & $12 \cdot 10$ \\
\hline $69 \cdot 52$ & $3 \cdot 80$ & $12 \cdot 56$ \\
\hline $75 \cdot 17$ & $5 \cdot 40$ & $11 \cdot 25$ \\
\hline $30 \cdot 14$ & $18 \cdot 37$ & $20 \cdot 66$ \\
\hline $50 \cdot 62$ & 6.96 & $21 \cdot 65$ \\
\hline $44 \cdot 09$ & $11 \cdot 79$ & $19 \cdot 43$ \\
\hline $65 \cdot 82$ & $2 \cdot 78$ & $12 \cdot 31$ \\
\hline
\end{tabular}

6-Mercaptopurine and 6-thioguanine are designed to disrupt the purine salvage pathway and to interfere with the normal supply of nucleotides for DNA synthesis. Both compounds eventually form the same abnormal 6-thioguanine nucleotides, although the way they are metabolised to produce the cytotoxic chemicals differs (McCormack \& Johns 1982). Inhibition of purine de novo synthesis reduces purine deoxyribonucleotide levels and can be demonstrated by the delay of cell progression through S phase and an inhibition of DNA synthesis. Indeed, Bokkerink et al. (1993) demonstrated a G2 arrest in human malignant $\mathrm{T}$ lymphoblasts after a $24-\mathrm{h}$ incubation with 6-mercaptopurine. 6-Thioguanine, however, is a cell cycle specific agent, killing cells in G1 and S phases (Le Page 1963). Although in our studies cell doubling times were slightly increased by both agents, it was perhaps surprising that no effects of these agents were observed on cell cycle events, particularly as both also inhibited early cell growth and clonal growth, with a lesser effect on cytotoxicity. Furthermore, the significant reduction in the numbers of BrdU-labelled cells observed in our studies is likely to be due merely to the competition between either agent and BrdU for uptake during purine nucleotide synthesis. What is possible, however, is that the level of toxicity observed with these agents is dependent on length and frequency of exposure, resulting from an accumulated toxicity, and thus the repeated daily exposure of chondrocytes in culture to these agents may produce greater effects than single exposures. In vivo studies have reported that, following daily administration for 5 days, 6-thioguanine is ten times more potent than 6-mercaptopurine (Adamson et al. 1994). This was certainly not the case in our studies, however, where a significantly greater effect of 6-mercaptopurine on cloning efficiency was observed.

Methotrexate is an antiproliferative agent that accumulates intracellularly as polyglutamate derivatives and inhibits DNA synthesis via inhibition of the enzyme dihydrofolate reductase (Van der Veen et al. 1996). In our studies we failed to observe any effects of this agent on the proliferative responses of the chondrocytes. Again this may be due to the absence in our studies of an examination of the cumulative effects of this agent with time. Certainly, long term low dose treatment with methotrexate can cause osteopathy with histologically proven reduction in bone turnover and matrix formation (Preston et al. 1993, Jaskiewicz et al. 1996).

The DNA damaging agents etoposide, actinomycin-D, cisplatin and carboplatin exhibit varying mechanisms of cytotoxicity. Etoposide is a topioisomerase II inhibitor which has been reported to induce an irreversible blockade of cells in the pre-mitotic phase of the cell cycle, leading to the accumulation of cells in the late S or G2 phases (Achterrath et al. 1982). Indeed, a G2 arrest and significant loss of the chondrocytes was observed in our studies, which was also characterised by the loss of cloning efficiency.

Actinomycin-D suppresses RNA synthesis (Perry \& Kelly 1970) although it is not known why some cells die after a brief exposure to this agent and others do not, nor why the cytotoxic effects are reversible for some cells and not for others. Certainly, in our studies this agent was extremely cytotoxic and an almost complete loss of chondrocytes was observed in all assays.

Part of the cytotoxic mechanism of cisplatin action involves the formation of intrastrand DNA cross-links between guanosine residues (Sherman et al. 1985), effects that were previously shown to be most pronounced during $\mathrm{S}$ phase. In our studies, an early $\mathrm{S}$ phase accumulation observed in chondrocyte cells treated with cisplatin was followed by their arrest in G2/M and subsequent cell loss.

Carboplatin was shown by Micetich et al. (1985) to cause similar types of DNA lesions to cisplatin, but carboplatin does this more slowly than cisplatin. Carboplatin was certainly significantly less potent than 
cisplatin in terms of its cytotoxic effects on chondrocyte cells in monolayer culture, although in suspension culture both agents were able completely to abolish colony formation.

In summary, in our studies the glucocorticoids and to some extent the purine salvage pathway inhibitors exert cytostatic effects on the chondrocytes whilst the DNA damaging agents are cytotoxic. What is clear, however, is the importance of determining the long-term effects of these agents on chondrocyte differentiation and maturation and their subsequent recovery, if any. Of particular interest is the observation that under certain pathological conditions, mechanisms regulating the cellular height of the hypertrophic chondrocyte may be impaired without disturbing proliferative capacity. Furthermore, both GH and IGF-I have important roles in the regulation of longitudinal bone growth such that these peptides stimulate the chondrocytes at different stages of maturation. GH affects the chondro-progenitor, or stem cells and IGF-I affects the proliferative chondrocytes. Direct stimulation by $\mathrm{GH}$ sensitises the pre-chondrocytes and young differentiating cells to IGF-I (reviewed by Hunziker 1994). It is thus possible that both peptides could aid the recovery of chondrocytes following their treatment with these agents. However, long-term treatment with glucocorticoids in rheumatic diseases has been linked to reduced bone formation which, in turn, was suggested to be due to a decrease in the sensitivity of the target to IGF-I (Hansson et al. 1996). Furthermore, although we saw no effect with the agent methotrexate in our studies, this does not rule out the possibility of adverse effects following prolonged and/or repeated exposure with this agent or at different stages of chondrocyte maturation.

In conclusion, these results have important implications for the control of longitudinal bone growth in vivo and the consequences of treatment for childhood malignancies. Further studies will be undertaken to determine the mechanism(s) of agent action in these cells as well as their role during the overall regulation of chondrocyte maturation and the possible contribution of treatment schedules to these effects.

\section{Acknowledgements}

This work was supported by the Christie Hospital Endowment Fund

\section{References}

Achterrath W, Nierdele N, Raettig R \& Hilgard P 1982 Etoposide Chemistry, pre-clinical and clinical pharmacology. Cancer Treatment Reviews 9 3-13.

Adamson PC, Poplack DG \& Balis FM 1994 The cytotoxicity of thioguanine vs mercaptopurine in acute lymphoblastic leukemia. Leukemia Research 18 805-810.
Baron J, Oerter Klein K, Colli MJ, Yanovski JA, Novosad JA, Bacher JD \& Cutler GB 1994 Catch-up growth after glucocorticoid excess: a mechanism intrinsic to the growth plate. Endocrinology $\mathbf{1 3 5}$ 1367-1371.

Benya PD \& Shaffer JD 1982 Dedifferentiated chondrocytes reexpress the differentiated collagen phenotype when cultured in agarose gels. Cell 30 215-224.

Bokkerink JPM, Stet EH, Deabreu RA, Damen FJM, Hulscher TW, Bakker MAH \& Van Baal JA 1993 6-Mercaptopurine: cytotoxicity and biochemical pharmacology in human malignant $\mathrm{T}$ lymphocytes. Biochemical Pharmacology 45 1455-1463.

Cancedda FD, Gentili C, Manduca P \& Cancedda R 1992 Hypertrophic chondrocytes undergo further differentiation in culture. Journal of Cell Biology 117 427-435.

Davies HA, Didcock E, Didi M, Ogilvy-Stuart A, Wales JK \& Shalet SM 1994 Disproportionate short stature following cranial irradiation and combination chemotherapy for leukaemia. Archives of Diseases in Childhood 70 472-475.

Falliers CJ, Szentivanyi J, Jorgensen JR \& Vukantz SC 1963 Childhood asthma and steroid therapy have influences on growth. American Journal of Diseases in Childhood 105 127-137.

Hansson A, Hehenberger K \& Thoren M 1996 Long term treatment of swiss 3T3 fibroblasts with dexamethasone attenuates MAP kinase activation induced by IGF-I. Cell Biochemistry and Function 14 121-129.

Hunziker EB 1994 Mechanism of longitudinal bone growth and its regulation by growth plate chondrocytes. Microscopy Research Techniques 28 505-519.

Jaskiewicz K, Voight H \& Blakolmer K 1996 Increased matrix proteins, collagen and transforming growth factor are early markers of hepatotoxicity in patients on long-term methotrexate therapy. Journal of Toxicology and Clinical Toxicology 34 301-305.

Kaspers GJ, Veermen AJ, Popp-Snijders C, Lomecky M, Van-Zantwijk CH, Swinkels LM, Van-Wering ER \& Pieters R 1996 Comparison of the antileukaemic activity in vivo of dexamethasone and prednisolone in childhood acute lymphoblastic leukaemia. Medical and Pediatric Oncology 27 114-121.

Kember NF 1971 Growth hormone and cartilage cell division in hypophysectomised rats. Cell and Tissue Kinetics 4 193-199.

Le Page GA 1963 Basic biochemical effects and mechanisms of action of 6-thioguanine. Cancer Research 23 1202-1206.

Lindahl A, Isgaard J \& Isaksson OGP 1987 GH in vivo potentiates the stimulatory effect of IGF-I in vitro on colony formation of epiphyseal chondrocytes isolated from hypophysectomised rats. Endocrinology 121 1070-1075.

McCormack JJ \& Johns DG 1982 Purine antimetabolites. In Pharmacologic Principles of Cancer Treatment, pp 213-228. Ed B Chabner. Philadelphia: WB Saunders.

Micetich KC, Barnes D \& Erickson LC 1985 A comparative study of the cytotoxicity and DNA damaging effects of cis-(diammino)(1,1-cyclobutanedicarboxylato)-platinum (II) and cis-diamminedichloroplatinum (II) on L1210 cells. Cancer Research 45 4043-4047.

Morris MJ 1981 In vitro effects of anti-leukaemic drugs on cartilage metabolism and their effects on somatomedin production by the liver. PhD Thesis, Manchester University.

Ogilvy-Stuart AL \& Shalet SM 1995 Growth and puberty after GH treatment after irradiation for brain tumours. Archives of Diseases in Childhood 73 141-146.

Olshan JS, Gubernick J, Packer RJ, D'Angio GJ, Goldwein JW, Willi SM \& Moshang T 1992 The effects of adjuvant chemotherapy on growth in children with medulloblastoma. Cancer 70 2013-2017.

Pairault J \& Lasnier F 1987 Control of the adipogenic differentiation of 3T3-F442A cells by retinoic acid, dexamethasone, and insulin: a topographic analysis. Journal of Cell Physiology 132 279-286. 
Perry RP \& Kelly DE 1970 Inhibition of RNA synthesis by actinomycin D: characteristic dose response of different RNA species. Journal of Cell Physiology 76127.

Preston SJ, Diamond T, Scott A \& Laurent MR 1993 Methotrexate osteopathy in rheumatic disease. Annals of the Rheumatic Diseases $\mathbf{5 2}$ $582-585$.

Price JS, Oyajobi BO \& Russell RGG 1994 The cell biology of bone growth. European Journal of Clinical Nutrition 48 S131-S149.

Sherman SE, Gibson D, Wang AH \& Lippard SJ 1985 X-ray structure of the major adduct of the anticancer drug cisplatin with DNA: cis-[Pt(NH3)2(d(pGpG))]. Science 230 412-417.

Skehan P, Storeng R, Scudiero D, Monks A, McMahon J, Vistica D, Warren JT, Bokesch H, Kenney S \& Boyd MR 1990 New

colorimetric cytotoxicity assay for anticancer drug screening. Journal of the National Cancer Institute 82 1107-1112.
Van Metre Jr TE \& Pinkerton Jr HL 1959 Growth suppression in asthmatic children receiving prolonged therapy with prednisone or methyl-prednisone. Journal of Allergy 30 103-113.

Van der Veen MJ, Scheven BAA, Van Roy JLAM, Damen CA, Lafeber FPJG \& Bijlsma JWJ 1996. In vitro effects of methotrexate on human articular cartilage and bone-derived osteoblasts. British Journal of Rheumatology 35 342-349.

Wollner N, Wachtel AE, Exelby PR \& Centore D 1980 Improved prognosis in children with intra-abdominal non-Hodgkins lymphoma following $\mathrm{LSA}_{2} \mathrm{~L}_{2}$ protocol chemotherapy. Cancer 45 p3034-p3039.

Received 11 June 1997

Accepted 24 November 1997 